\title{
Collaborative Disaster Management: An Interdisciplinary Approach
}

\author{
Ovidiu Noran \\ Griffith University Australia, School of ICT \\ O.Noran@griffith.edu.au
}

\begin{abstract}
Large scale natural and man-made catastrophic events, triggered or augmented by regional conflicts, climate change and new disease strains appear to be steadily increasing in intensity and frequency. Proper preparation, response and recovery are essential to cope with and survive large-scale disasters; unfortunately however, the institutions responsible for delivering emergency response services form a heterogeneous set that often underperforms due to lack of proper interoperation and collaboration. New innovative, holistic and integrated models, representing all essential aspects of the disaster events and response team participants are necessary to successfully meet these new challenges. Based on previous research and applications, this paper argues that the necessary artefacts can be built using an interdisciplinary, industry-based paradigm enabled by advances in the Interoperability, Collaborative Networks and Enterprise Architecture disciplines. This combined approach aims to provide a sound platform for efficient disaster response delivered by agile and synergic task force teams.
\end{abstract}

\section{Introduction}

The rate and force of natural and man-made disasters, whether triggered or augmented by new strains of drug-resistant diseases, regional conflicts and climate change, appears to be on the rise. In this context, it is nowadays essential to promptly and effectively prevent, prepare for, respond to and recover from catastrophic events. Governments worldwide usually react to this challenge by creating specific policies, departments and organisations. 'Disaster management' organisations (DMOs) operate in a complex environment featuring diverse history, tradition, geographic location and culture, level and type of governance etc; the resulting organisational diversity of the DMOs requires significant effort to achieve proper and effective collaboration (Whitman \& Panetto, 2006). As coping with large scale catastrophic events typically demands resources and capabilities beyond those of any individual organisation, the effective cooperation of DMOs at all necessary levels and addressing all relevant aspects is essential (Australian Psychological Society, 2013; Kapucu, Arslan, \& Demiroz, 2010; Trakas, 2012; World Health Organisation, 2011). Failing to achieve effective collaboration in disaster management typically has dire consequences, including loss of property and human life. 


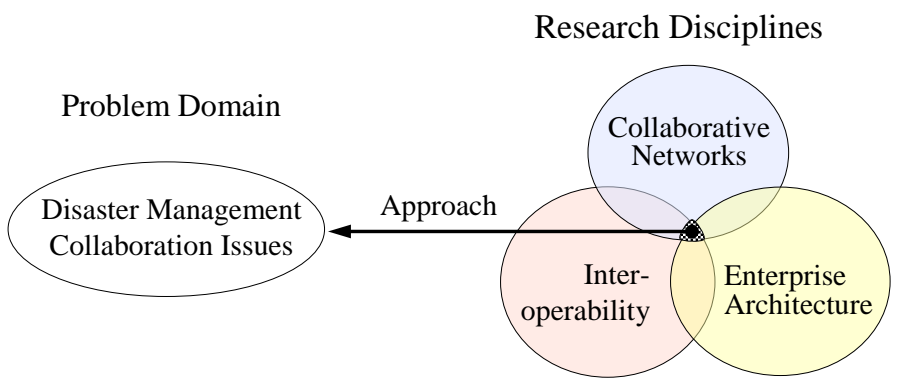

Fig.1. A multidisciplinary approach to advance collaborative disaster management

The paper adopts an interdisciplinary approach to disaster management collaboration drawing upon knowledge accumulated by state-of-the-art research in Interoperability, Collaborative Networks and Enterprise Architecture (see Fig.1). It is expected that that this approach will promote an integrated holistic, life cycle-based analysis and architectural design approach covering all aspects deemed relevant for the disaster management universe of discourse.

\section{Current Issues in Collaborative Disaster Management}

The operation of emergency services is typically legislated at state, national and international levels (e.g. (Australian Government, 2011; Federal Emergency Management Agency, 2011; Government of South Australia, 2004; United Nations International Strategy for Disaster Reduction Secretariat (UNISDR), 2011)). However, merely instructing organisations to cooperate using high-level generic directives does not bring about true collaboration; the consequences are increased response times, confusion about the situation on the ground and sometimes even dispute as to who, where and when is in charge. Wilson et al. (2005) reinforce this point by stating that collaboration does not automatically occur but rather must be "constructed, learned [...]" and importantly, “[...] once established, protected” (ibid.). Like most human-related processes, collaboration cannot be successfully forced on the participants or achieved in a short period.

Coordination in crisis situations is also difficult due to incompatibilities in infrastructure and difficulty in filtering and validating the typical flood of information generated during disaster events. For example, inconsistency in alert notice types and formats may delay intervention and hinder warnings by fuelling a 'cry wolf' situation where the population is saturated with ambiguous and/or irrelevant messages (Queensland Floods Commission of Enquiry, 2011; Victorian Bushfires Royal Commission, 2009). This may lead to sub-optimal prevention and response by intended recipients and potential property and life loss. Unfortunately, efforts to standardise warning message protocols are still rather localised, with low take-up rates (Moore, 2010; OASIS, 2005).

Various documents, inquiries, reviews and reports (('t Hart, Boin, Stern, \& Sundelius, 2005; Brewin, 2011; Igarashi, Kong, Yamamoto, \& McCreery, 2011; 
Queensland Floods Commission of Enquiry, 2011; United Nations International Strategy for Disaster Reduction Secretariat (UNISDR), 2011; Victorian Bushfires Royal Commission, 2009; Wiese, 2006), etc), suggest that the root causes of current shortcomings could in fact be the inadequate information flow and quality between the participants (Prizzia \& Helfand, 2001; Wickramasinghe \& von Lubitz, 2007), owing mostly to incompatibilities originating in heterogeneity, lack of trust, organisational confusion and even competition fallacies. Thus, true collaboration is intricate and multifaceted, involving information, processes, resources and organisational cultures of the participants (Kapucu et al., 2010; Trakas, 2012), as well as their information systems that reflect and manage most of these aspects (Stohr \& Konsynsky, 1992).

It is also essential to point out that the collaboration capability of the participants involved in a disaster management effort also fluctuates in relation to their current life cycle phase/s. For example, the collaborative potential and agility of an organisation may decrease during its re-engineering, involving concurrent operation, analysis and design life cycle phases. Currently, this important aspect appears to be largely overlooked with most of the modelling performed in a snapshot-like manner.

An important part of disaster management is represented by health-related incidents. Healthcare has made significant advances in the last century, such as the development and wide use of vaccines, eradication of serious diseases and large reductions in communicable disease epidemics and chronic illnesses (Fielding, 1999; World Health Organization, 1998). Unfortunately however, nowadays we are still confronted with global health hazards owing to causes such as new strains of diseases (Kilbourne, 2006) and climate change (Donohoe, 2003). Typical psychological effects triggered by disaster events such as uncertainty, anguish, confusion, panic etc are amplified in pandemic-type situations and thus claim appropriate and specific collaboration preparedness of the participant organisations (U.S. Dept of Health and Human Services, 2005; World Health Organisation, 2011), achieved in advance, based on frameworks with a strong ethics component (NZ National Ethics Advisory Committee, 2006; Thompson, Faith, Gibson, \& Upshur, 2006).

Owing to the urgency involved and often in the context of slow response of some task force members, the higher ranking organisation/s may be tempted to override, exclude or replace some participants, adopting a 'central command'-type approach in preference to a cooperative one (Waugh, 1993). This is not desirable, as successful disaster management (including healthcare crises) relies on a wide range of community economic, social-psychological, and political resources. This cooperation brings communities together, gives them a sense of usefulness (ibid.) and thus alleviates negative psychological effects of disaster events. The disaster management federalisation approach offered as an alternative to central command has also achieved sub-optimal results in the past as reflected in criticism expressed in the relevant literature ('t Hart et al., 2005; Clark, 2006; Wiese, 2006). The adoption of military-type network-enabled capabilities in disaster management (von Lubitz, Beakley, \& Patricelli, 2008) has also been found to have limited applicability due to potential over-reliance on failure-prone civilian communication infrastructure.

Piece-meal solutions to various collaborative disaster management barriers are emerging. Thus, Baker et al. (2006) argue that the typically divergent perceptions and expectations of the task force parties involved (Krogstad, Hofoss, \& Hjortdal, 2004), 
often augmented by strong hierarchy and marked difference in status between partners (Ramanujam \& Rousseau, 2006), can be dealt with by the higher ranking participants promoting collaboration and trust through a participatory and inclusive approach.

Literature further argues that collaborative disaster management can be enhanced by modelling and participatory design (Kristensen, Kyng, \& Palen, 2006) aimed at integrating scientific but also administrative and political aspects into a whole-system approach (Moghadas, Pizzi, Wu, \& Yan, 2008; Utah Department of Health, 2007; World Health Organisation, 2011). The essential life cycle aspect is somewhat addressed (Australian Government, 2011; Shimada, Kitajima, Fuchino, \& Takeda, 2012) however not seen as a context to all other viewpoints and participants.

Thus, poor aspect coverage (including life cycle), lack of commonly understood integrated models and a missing mature cooperation paradigm appear to be the major obstacles in achieving suitable collaborative preparedness. Overcoming these barriers requires access to a multitude of interdisciplinary information and knowledge not always obvious or easily accessible to planners and disaster managers. This paper attempts to propose a way forward in this regard.

\section{Disaster Management Interoperability: Approach and Aspects}

Successful disaster management cooperation involves the will and capability of the participating organisations to work together in an optimal way. The concept of 'interoperability' (sometimes accompanied by 'maturity') is often used as a measure of cooperation capability ((DoD Architecture Framework Working Group, 2004; Guédria, Chen, \& Naudet, 2009)). Note that interoperability is understood here as enabling the use and exchange of information but also as ability to perform a function on behalf of another entity (Vernadat, 1996). The analysis of interoperability in the disaster management domain must include some important aspects:

- what is the required interoperability extent?

- what components / aspects need to interoperate?

- how can it be ensured that all necessary aspects are covered ?

- how can it be ensured that the interoperability achieved is sustainable in time?

Each disaster event is quite unique; thus, there is no 'one size fits all crisis situations' DMO interoperability level. At a minimum, the participating organisations' systems should be compatible, so at least they don't hinder each other's operations (see Fig.2). 

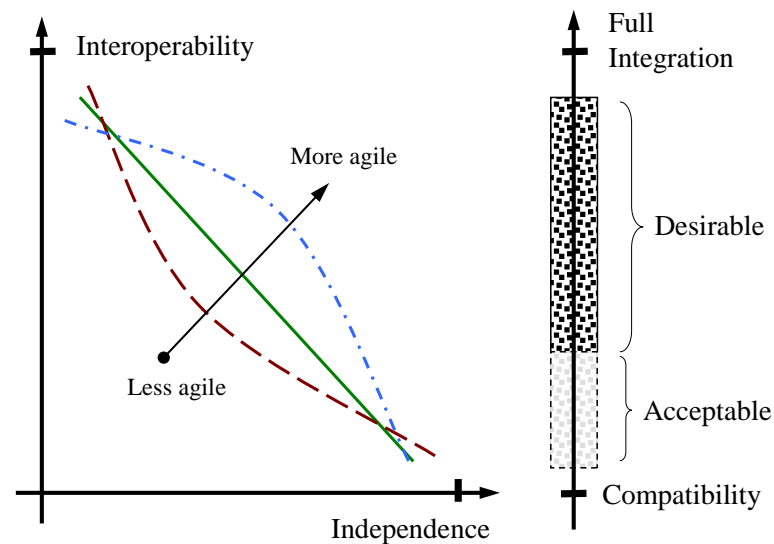

Fig.2. Acceptable vs. desirable interoperability levels in disaster management

Full integration (if at all achievable) is not desired in this case as it would imply that the members of the task force created by the DMOs could not fully function independently. In an emergency situation, some response team members may be affected or even cease to function; the other participants should be able to continue without significant performance loss (see for example the ARPANET 'resilient network' concept espoused by Heart, McKenzie, McQuillian, \& Walden (1978)) and perhaps compensate for the failed or ailing members. Coordination can also be severely hindered by communication infrastructure breakdown (Crawford, 2012; Queensland Floods Commission of Enquiry, 2011); in this situation, the participants should be able to autonomously carry on their duties for a certain amount of time. Such capabilities require preparedness acquired in advance based on commonlyagreed procedures and shared knowledge and continuously monitored and updated to maintain their relevance and consistency.

\subsection{Disaster Management Interoperability Approach}

In reviewing the relevant research and body of knowledge we have found that ISO14258 (2005) establishes several ways to achieve interoperability: integrated (common format for all models), unified (common format at meta level) and federated (participants negotiating an ontology as they go to achieve a shared understanding of models). In the case of DMOs, neither full integration nor federalisation appeared to have achieved the desired results, mainly due to the organisational heterogeneity of DMOs and the impracticality to negotiate in real time during disaster response.

The unified approach (presumably the most suited to this situation) requires only the ontology to be negotiated in advance. Unfortunately, notwithstanding significant advances in ontology integration (Farquhar et al., 1995; Pinto, Prez, \& Martins, 1999), currently the only sustainable solution to semantic disaster management interoperability appears to be DMOs 'spending time together' to agree on the meanings associated with the concepts used to exchange knowledge. 


\subsection{Disaster Management Interoperability Aspects}

The interoperability aspects relevant to disaster management have been represented and ranked in Fig. 3 using Chen's Interoperability Framework (2006) enriched with viewpoints from ISO14258, European Interoperability Framework (EIF)(2004), the IDEAS project (2003) and the ATHENA Interoperability Framework (AIF)(2004).

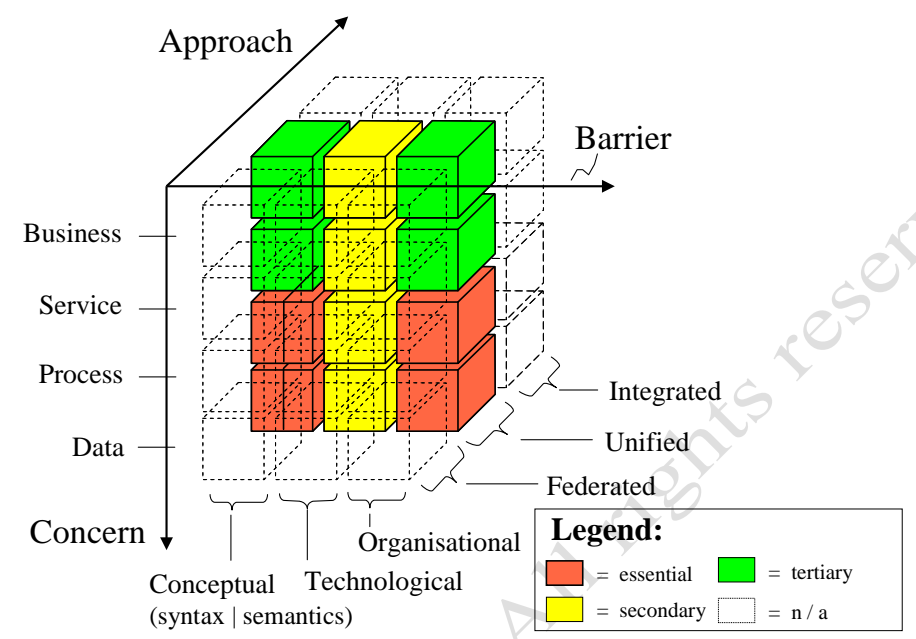

Fig. 3. An interpretation of Chen's Interoperability Framework (2006) from the point of view of ISO14258, EIF, IDEAS and ATHENA AIF

As can be seen, the data and process aspects on the ATHENA-inspired 'concern' axis have been ranked as most stringent in DMO collaboration. This is because typically, the ability to extract and exchange data from heterogeneous sources, delivering a large amount of (often unreliable) data during disaster events, is paramount to being aware of the conditions on the ground and avoiding potentially life-threatening situations for emergency crews and population. In this case, prior agreements on data format and especially on its meaning are essential.

Organisational interoperability is an essential aspect in disaster management, as task force participants typically exhibit significant organisational structure diversity. The issues identified by Chen (2006) based on the EIF (2004), namely responsibility, authority and type of organisation can all impact heavily on the functionality of a disaster management task force. In a crisis situation, the roles and hierarchy must be clear to all task force members from the beginning so that the response team can focus on managing the disaster event rather than spend critical time figuring out its own modus operandi (who does what, who is in charge etc).

Cultural interoperability (described e.g. by Whitman and Panetto (2006)) appears to be one of the hardest obstacles to overcome. Similar to achieving semantic interoperability, the only current solution appears to be the regular immersion of the participant organisations in each other's cultures, which facilitates the transfer and conversion of tacit and explicit knowledge between the participants.

A recurring concept through all the aspects analysed above is the 'co-habitation' of the organisations that will form disaster management task forces, as a prerequisite 
towards the achievement of true interoperability, be it functional, informational, organisational or cultural. Commercial practice shows that the 'Collaborative Networks' approach (Camarinha-Matos, Afsarmanesh, Galeano, \& Molina, 2009) and their associated concepts and artefacts are able to effectively support this approach; therefore, this paper proposes the adaptation of this paradigm to meet collaboration challenges as detailed in Section 4. The modelling of this customised approach is then performed in an integrated and inclusive life cycle-based manner using Enterprise Architecture artefacts as detailed in Section 5.

\section{Collaborative Networks for Disaster Management}

The DMOs' situation resembles the position of commercial enterprises that need to cope with a global business environment requiring them to tackle projects beyond their own resources and knowledge. A typical response in this case is for the companies to set up or join so-called Collaborative Networks (ibid.) defined as pragmatic and commercial but also social systems composed of commitments who absorb uncertainty, reduce complexity (Neumann, de Santa-Eulalia, \& Zahn, 2011) and promote trust (Beckett \& Jones, 2012; Msanjila \& Afsarmanesh, 2010). Another useful analogy can be found in Defence, where allied armed forces prepare for effective cooperation in crisis situations by employing standardised agreements and joint exercises (NATO, 2006). DMOs may have full time, militarised, voluntary and reserve personnel depending on the geographical location and local legal and administrative situation. This enables the use of concepts from both commercial and military areas provided proper customisation is performed for the specific scenario.

Collaborative Networks (CNs) are created in the industry in order to act as 'breeding environments' for Virtual Organisations (VOs). A VO is a group of companies that act as one for a limited time in order to bid for, win and complete projects requiring combined resources and know-how; at the end of the project(s) the VO usually dissolves. One or more 'lead partners' may be present in a CN based on their size, influence, etc. CN partners may take part in one or several VOs at any given time.

The CN concepts need to be customised for application to the disaster management area. Thus, the time available for the set-up of a disaster management VO (here, more appropriately called a 'Disaster Management Task Force' - DMTF) is significantly shorter than that available for a commercial project bidding process. In addition, the 'Disaster Management Collaborative Network' (DMCN), its participants and the DMTF(s) produced will operate under tight legal operational guidelines set by relevant Governments and national and international frameworks (e.g. (Federal Emergency Management Agency, 2011; World Health Organisation, 2011)).

The commercial and competitive motivations of the typical CN participants will translate in this case into the urgency to achieve proper efficiency and interoperability reflected in lives and property rescued, rather than make a profit. The usual create / join / remain / leave the $\mathrm{CN}$ decision processes would be mandated from outside (or by the lead partner/s, here most likely government agencies) for most participants. Reference models (patterns) classified on disaster type and location (such as flooding, 
tornadoes, wildfires, earthquakes etc (Ellis, Kanowski, \& Whelan, 2004)) can be created from lessons learned in past disaster relief efforts and used to refine future DMTFs. It must be noted however that reference model usefulness may be limited due to extensive customisation required by the typical diversity in scale and type of incidents (Tierney \& Quarantelli, 1989).

The DMTF(s) produced by the DMCN will be set up for and assigned a specific disaster management project relating to a particular disaster event, or combination thereof. Specific cooperation aspects relating to management, communication infrastructure, and other organisational interoperability issues would have been sorted out in advance within the DMCN, ensuring a prompt and appropriate task force response and thus addressing a frequent weakness identified in past crisis management efforts (Trakas, 2012).

\section{The Life Cycle Context and Enterprise Architecture}

All entities, including those involved in disaster management, go through a set of life cycle phases, whose succession in time form the entities' life histories (ISO/IEC, 2005). Interoperability requirements are inherently linked to life history as they vary during each life cycle phase; therefore, it is essential that the analysis of possible interoperability improvements is performed in a life cycle context. It is hereby argued that an optimal way to integrate the life cycle aspect into interoperability is by using an Enterprise Architecture (EA) approach.

While there are many definitions for EA, the author takes the view that it expresses the ontology of enterprise change. Thus, EA provides a holistic approach to business evolution and agility "by creating, communicating and improving the key requirements, principles and models that describe the enterprise's future state." (Gartner Research, 2012). Importantly, “[...] EA comprises people, processes, information and technology of the enterprise, and their relationships to one another and to the external environment" (ibid.). This EA definition is in agreement with the view of CNs as social systems composed of commitments (Neumann et al., 2011) and related to information systems as a socio-technical system (Pava, 1983) with voluntaristic people (McGregor, 1960) in a complex organisational, political and behavioural context (Iivari, 1991; Keen \& Scott Morton, 1978). As such, it encourages the use of EA as an integrated, multi-perspective approach for analysing the impact of the interactions between disaster management network participants in the context of their life cycles.

To illustrate how EA artefacts and methods can guide and enrich the analysis and improvement of DMCN and DMTF interoperability, we have selected a generalised architecture framework (AF) (subsuming other mainstream AFs), defined in Annex A of ISO15704 (2005) as the 'Generalised Enterprise Architecture and Methodology' (GERAM). The modelling framework (MF) of GERAM's reference architecture (GERA) contains a repository of aspects that can all be represented on an orthogonal life cycle dimension. GERA's MF has been previously used in enterprise information systems modelling, in management, manufacturing, environment and many other areas (e.g. see (Mo, 2007; Noran, 2008, 2009, 2012a, 2012b; Saha, 2007)). 

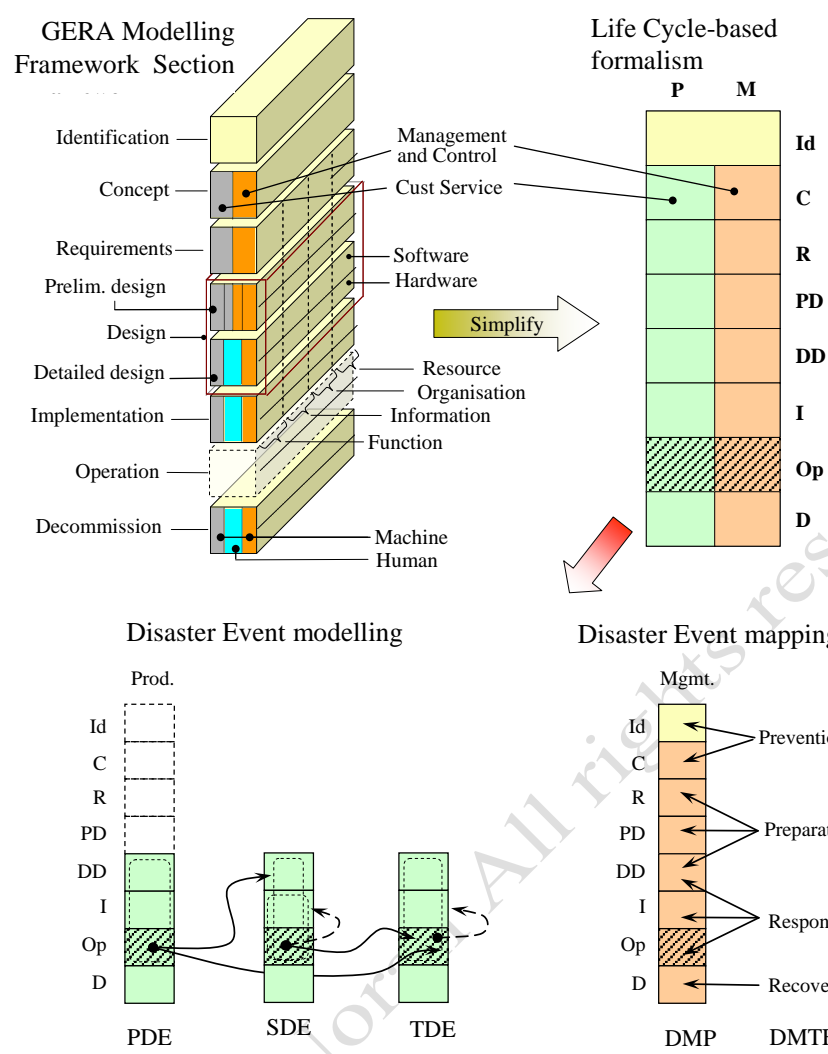

Disaster Event mapping

Legend:

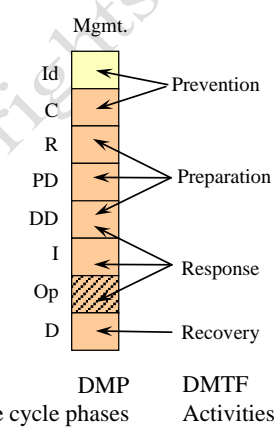

$\mathrm{PDE} / \mathrm{SDE} / \mathrm{TDE}=$ Primary $/$ Secondary $/$ Tertiary Disaster Event;

DMP $=$ Disaster Mgmt Project; DMTF $=$ Disaster Management Task Force

$\square=$ Production view $\square$ = Management view $\bullet-\rightarrow$ = Possible scenario

Fig. 4 Disaster event modelling and mapping using the GERA life cycle construct

Subsets of the GERA MF can be used to create modelling constructs such as shown in Fig. 4 top, which can become building blocks for dynamic business models requiring a life cycle background and the integration of several aspects in the same diagram. Thus, aspects previously identified as significant in tackling disaster management interoperability (function, information, organisation, human etc) can be represented together as shown in Fig. 4 upper left. Aspects can also be grouped using projections; for example, the two-dimensional structure shown in Fig. 4 upper right can be used to build separate diagrams for information, function, resources and so on.

Figure 4 lower left uses the GERA-based modelling construct to show a high-level representation of a disaster event, with its relevant life cycle phases and possible influences to / from other events. Thus, it can be conveyed for example that a Primary Disaster Event (PDE) can trigger or influence other events (SDE, TDE). For example, an earthquake event (PDE) can trigger a tsunami (SDE) that can in turn trigger a partial nuclear meltdown or a pandemic (TDE). This modelling approach is flexible, 
e.g. it can be shown that PDEs can also influence TDEs directly. Events such as chain reactions can also be shown (arrows from Operation to Implementation within same entity). Here, the GERA MF's 'Detailed Design' and 'Implementation' life cycle phases refer to features of the event - e.g. earthquake time, epicentre and duration, tsunami spread, wave speed, height, or pandemic type, spread and infectiousness etc.

The lower right hand side of Fig. 4 shows how the life cycle phases of a disaster management project (DMP) can be mapped to the typical disaster management activities (Australian Government, 2011) performed by the DMTF that sets up and operates that DMP. Such high-level diagrams are useful to help stakeholders 'break the ice' and grasp an initial common understanding of the disaster event and management aspects, thus overcoming some interoperability semantic barriers that may delay DMP kick-off and subsequently hinder DMTF response

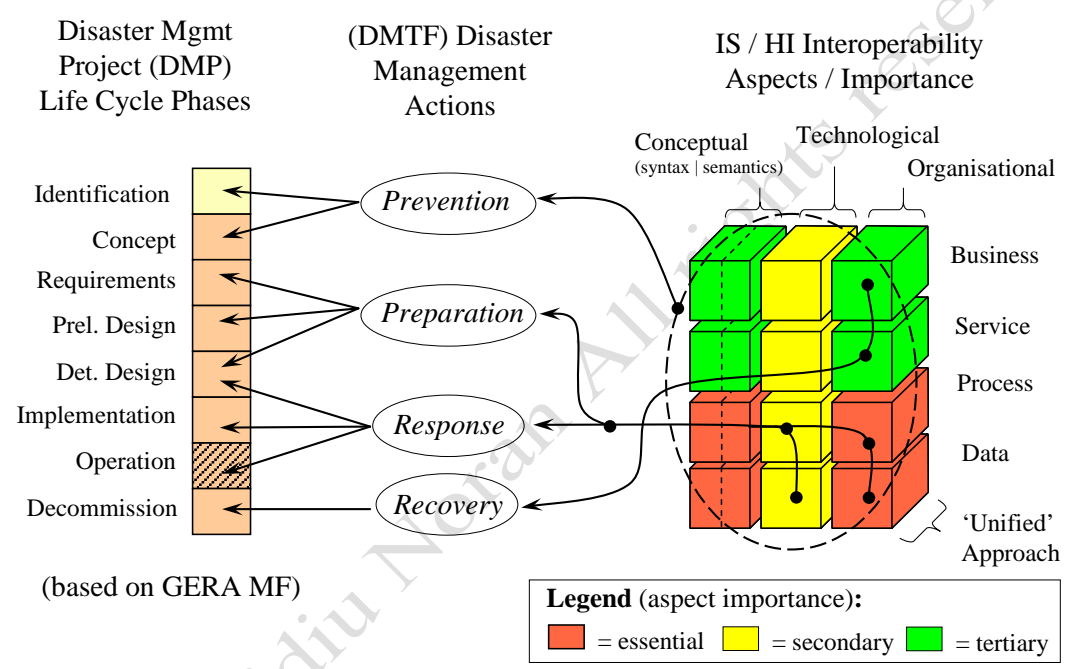

Fig. 5 Mapping Interoperability aspects on disaster management actions and DMP life cycle

Figure 5 uses the previously described interoperability framework and the GERA MFbased life cycle modelling construct in order to show how the relevance and applicability of the interoperability aspects depend on the specific life cycle phases of the disaster event and the DMTFs' actions to address them. The figure shows particular interoperability aspects taking precedence during specific disaster event life cycles; for example, as mentioned, during the response phase data and process interoperability aspects are paramount as accurate and fresh data is required and processes may need to be performed interchangeably due to potential disability of some DMTF participants (or the need to involve additional / replacement members from the DMCN). During recovery, which typically takes an extended period of time and requires less real-time responsiveness, business and service interoperability aspects take precedence.

Table 1 summarizes the main issues identified in DMO collaboration and the potential benefits brought by a combined Interoperability, CN and EA solution. 
Table 1. Collaborative disaster management barriers and solutions offered by employing an interdisciplinary Interoperability, CN and EA approach and artefacts.

\begin{tabular}{|l|l|}
\hline \multicolumn{1}{|c|}{ Disaster Management Issue } & \multicolumn{1}{|c|}{ Help from Interoperability, EA and CN } \\
\hline \hline Divergent perceptions of the participants' roles & Clear, agreed roles for Network and Task force participants \\
\hline Lack of trust between partiticipants & Trust building in advance within the Network \\
\hline $\begin{array}{l}\text { Poor life cycle management of task forces / } \\
\text { collaborative disaster management }\end{array}$ & $\begin{array}{l}\text { Intrinsic life cycle context to the creation and operation of } \\
\text { network and task forces }\end{array}$ \\
\hline $\begin{array}{l}\text { Difficulties setting up and operating Collaborative } \\
\text { Task Force (e.g. unclear rules, disagreement on } \\
\text { the present and future situations) }\end{array}$ & $\begin{array}{l}\text { Participatory design, inclusive approach by lead network } \\
\text { partner. Agreed upon models of Disaster Management } \\
\text { Collaborative Networks }\end{array}$ \\
\hline Focus on a limited set of interoperability aspects & A 'Whole-system' approach integrating all relevant aspects \\
\hline $\begin{array}{l}\text { Information sharing and cooperation impeded by } \\
\text { heterogeneity and hierarchy }\end{array}$ & $\begin{array}{l}\text { Information and process interoperability achieved at Network } \\
\text { level and reflected in the Task Forces created }\end{array}$ \\
\hline $\begin{array}{l}\text { Tendency to overrule rather than cooperate in task } \\
\text { forces }\end{array}$ & $\begin{array}{l}\text { Cooperation previously agreed upon and built into the Task } \\
\text { Forces created by the Network }\end{array}$ \\
\hline $\begin{array}{l}\text { Lack of preparedness to participate in a task force } \\
\text { on short notice }\end{array}$ & $\begin{array}{l}\text { Participant preparedness built in advance within the Network, } \\
\text { ready for fast Task Force creation }\end{array}$ \\
\hline $\begin{array}{l}\text { Difficult discovery and assessment of suitable } \\
\text { participants for an effective and agile task force }\end{array}$ & $\begin{array}{l}\text { Task Forces created promptly using pre-qualified Network } \\
\text { partners implementing agreed upon processes. } \\
\text { Interoperation and agility built in. }\end{array}$ \\
\hline
\end{tabular}

\section{Integrated Collaborative Disaster Management Modelling}

Although helpful in setting up the task force and disaster management project, Fig. 5 shows only the influence of the disaster event, management project and task force life cycles on the interoperability requirements. As a matter of fact, the DMOs, DMCN, DMTF and DMP interact with a plethora of entities and artefacts during their life history. These interactions must also be analysed in order to gain a whole-system view of the DMO, DMCN and DMTF interoperability endeavours. Figure 6 shows an information-based excerpt from the set of integrated models that need to be constructed, using the GERA-based construct previously presented in Fig. 4.

Thus, Fig. 6 depicts interoperability-related interactions for the Information (data) aspect of the GERA MF, in the previously described scenario of a collaborative network (DMCN) creating task forces (DMTFs) supervising disaster management projects (DMPs) that coordinate disaster event responses. Note that a complete modelling exercise (not possible here due to space limitations) should contain diagrams covering all the required aspects (e.g. also function, resources, organisation, risk, human, hardware, software, etc) as espoused by the stakeholders. The use of viewpoint combinations based on the same modelling framework (here, GERA MF) will facilitate producing and maintaining a coherent set of models.

The arrows in Fig. 6 show influences. For example, the participating DMOs need to interoperate during their Operation life cycle phase; however this may also imply some redesign (line between DMO1 and DMO2 linking Operation but also 'upper' life cycle phases). 


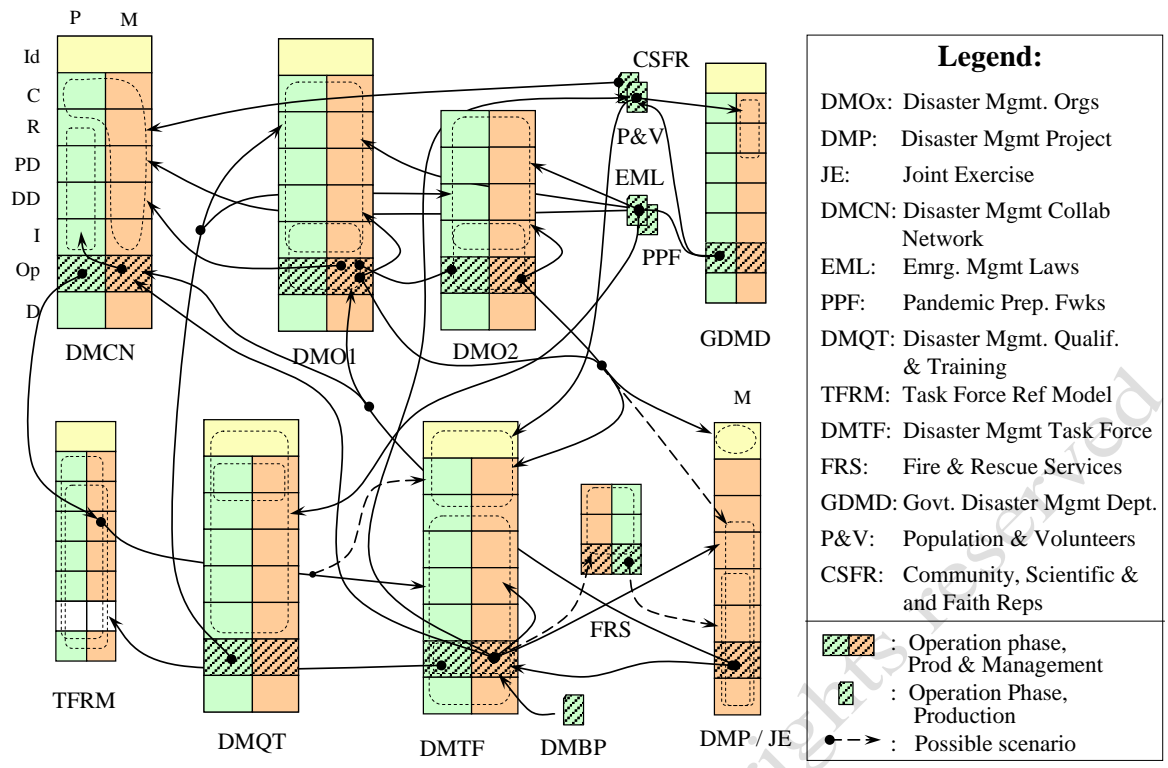

Life cycle phases: Id: Identification; $\mathrm{C}=$ concept; $\mathrm{R}=$ requirements, $\mathrm{PD}=$ preliminary design, $\mathrm{DD}=$ detailed design,

$\mathrm{I}=$ =implementation, $\mathrm{OP}=$ operation, $\mathrm{D}=$ decommissioning. Other aspects: $\mathrm{P}=$ Production / Service, $\mathrm{M}=$ =management

Fig. 6. High-level dynamic business model for a possible disaster management collaborative network, task force and project scenario (based on (Noran, 2011; Noran \& Bernus, 2011)).

The DMCN must be able to interoperate with DMTF it designs and creates; the same is true for the DMTF and the DMPs it creates and manages (arrows from DMCN to DMTF and DMTF to DMP). The dashed lines show possible scenarios, such as the external participation of additional organisations that do not enter the DMCN for various administrative, legislative etc reasons, or variable extents of involvement of the various organisations in the design of the DMTF (dashed arrow from DMCN to DMTF's Identification, Concept and Requirements life cycle phases).

Data interoperability (arrows) shown between the DMOs participating in a DMTF and between the DMTFs and population and volunteers $(\mathrm{P} \& \mathrm{~V})$ is paramount as it will directly influence the extent of lost property and casualties. Past experience and feedback from previous enquiries (Ellis et al., 2004; Queensland Floods Commission of Enquiry, 2011; Victorian Bushfires Royal Commission, 2009) has shown that two major goals of the disaster management interoperability improvement effort (partly reflected in Fig. 6) should be a) whether $\mathrm{P} \& \mathrm{~V}$ receive, understand, believe and act on DMTF warnings and directives and b) that DMTF participants can properly interoperate during the disaster event. Thus, warning messages should be designed to avoid ambiguity and maximise focus in relation to the local specific semantic interoperability requirements (language, technology type, habits etc). For example, the message format and distribution in a densely populated and developed area would likely differ from the one used in a sparsely populated region - at least until warning message standardisation efforts are successful, widely implemented and observed.

Importantly, some organisations shown in Fig. 6 should be able to redesign themselves to a certain extent (arrows from DMO, DMCN, DMTF Operation life 
cycle phase to their own upper phases). This reflects an essential capability to adapt (and thus be agile and resilient) in the face of changes in the situation and environment that are likely to occur briskly and unexpectedly during disaster events.

A 'Disaster Management Qualification and Training' organisation (DMQT - see e.g. (Queensland Government, 2011)) can assess and if applicable, provide training for potential participants in a DMCN so as to meet the network competency entry criteria.

The validity and effectiveness of the participants' interoperability (be it data, function, resources etc) can be tested by joint exercises (JEs) simulating disaster events; this will allow potential interoperability problems to surface and be tackled. The resilience and performance of DMTFs created can be also assessed and tuned in JEs through various scenarios with proper corrective action taken where applicable.

Note that high-levels model such as shown in Fig. 6 do not aim to provide all the details necessary for actual implementation upfront. Rather, their main purpose is to facilitate stakeholder consensus on the problems of the present state and support the selection of the optimal future state. Such models can provide checklists of the entities that need to be considered in the collaborative disaster management endeavour and spell out the interactions and influences between them, in the context of their life cycles. They can also represent autonomy and agility requirements, which is essential in disaster management. Once stakeholder consensus on the high-level models has been achieved, they can be decomposed and evolved into detailed design and implementation blueprints.

\section{Conclusions and Further Work}

Collaboration and interoperation are paramount in disaster management in order to meet the rising tide of natural and man-made disasters. Politics, hierarchy, divergent perceptions, lack of trust, dissimilar organisational cultures, shortage of mature collaboration paradigms and limited or missing integration and life cycle-based perspective of the participants' roles are decisive barriers that can be addressed by prior preparation in a suitable environment.

This paper has explored these difficulties and has argued that the much needed systems and organisational synergy and agility could be facilitated by adopting a multidisciplinary approach. The paper has also attempted to demonstrate this hypothesis by supplying a list of benefits and presenting a sample set of high-level modelling examples involving Interoperability, CN and EA viewpoints and artefacts.

The paper makes a theoretical contribution by emphasizing the connection and potential synergy between Interoperability, Collaborative Networks, Enterprise Architecture and Disaster Management research. It also makes a practical contribution by providing examples of how Collaborative Networks concepts can be employed from an Interoperability perspective making use of Enterprise Architecture frameworks in order to model integrated collaborative solutions to current imperative disaster management challenges.

The proposed approach will be further developed and applied to several case studies in various areas in order to verify, validate and refine it. 


\section{References}

't Hart, Paul, Boin, Arjen, Stern, Eric, \& Sundelius, Bengt. (2005). The Politics of Crisis Management: Public Leadership under Pressure. Cambridge UK: Cambridge University Press. ATHENA (2004). State of the art of Enterprise Modelling Techniques and Technologies to Support Enterprise Interoperability. Deliv D.A1.1.1 Retrieved Mar 30, 2011, from http://www.athena-ip.org

Australian Government. (2011). Attorney's General's Office - Emergency Management in Australia Retrieved Mar 30, 2011, from http://www.ema.gov.au/

Australian Psychological Society. (2013). Disaster Response Network (DRN) Retrieved April, 2013, from http://www.psychology.org.au/medicare/drn/

Baker, D., Day, R., \& Salas, E. (2006). Teamwork as an essential component of high reliability organizations. Health Services Research, 41(4), 1577-1598.

Beckett, R., \& Jones, M. (2012). Collaborative network success and the variable nature of trust. Production Planning and Control, 23(4), 240-251.

Brewin, Bob. (2011). Tsunami response reveals poor radio interoperability Retrieved April, 2012, from http://www.nextgov.com/nextgov/ng_20110415_3972.php

Camarinha-Matos, L, Afsarmanesh, H., Galeano, Nathalie, \& Molina, Arturo. (2009).

Collaborative networked organizations - Concepts and practice in manufacturing enterprises. Computers and Industrial Engineering, 57(1), 46-60.

Chen, D. (2006). Framework for Entrerprise Interoperability Retrieved July, 2011, from http://www.fines-cluster.eu/fines/jm/Download-document/53-Framework-for-EnterpriseInteroperability-Chen.html

Clark, J. L. (2006). Practical aspects of federalizing disaster response. Critical Care, 10, 107113.

Crawford, Susan. (2012). Why Cell Phones Went Dead After Hurricane Sandy Retrieved February, 2013, from http://www.bloomberg.com/news/2012-11-15/why-cell-phones-wentdead-after-hurricane-sandy.html

DoD Architecture Framework Working Group. (2004). DoD Architecture Framework Ver 1.0 Retrieved Feb 2007, 2007, from http://www.dod.mil/cio-nii/docs/DoDAF_v1_Volume_I.pdf, http://www.dod.mil/cio-nii/docs/DoDAF_v1_Volume_II.pdf

Donohoe, M. (2003). Causes and health consequences of environmental degradation and social injustice. Social Science and Medicine, 56(3), 573-587.

EIF. (2004). European interoperability framework for pan-European eGovernment services. Luxembourg: Interoperable Delivery of European eGovernment Services to public Administrations, Businesses and Citizens (IDABC).

Ellis, S., Kanowski, P., \& Whelan, R. (2004). National inquiry into bushfire mitigation and management. Canberra. Retrieved from http://www.ema.gov.au/www/emaweb/emaweb.nsf/Page/Volunteers2

Farquhar, A., Fikes, R., Pratt, W. , Rice, J. (1995), ,, Technical Report KSL-95-63, Knowledge, \& Systems Laboratory, Stanford University. (1995). Collaborative Ontology Construction for Information Integration - Technical Report KSL-95-63. Stanford University: Knowledge Systems Laboratory.

Federal Emergency Management Agency. (2011). National Response Framework Retrieved Mar 30, 2011, from http://www.fema.gov/pdf/emergency/nrf/about_nrf.pdf

Fielding, Jonathan E. (1999). Public Health in the Twentieth Century: Advances and Challenges. Annual Reviews in Public Health, 20, xiii-xxx.

Gartner Research. (2012). IT Glossary, 2012, from http://www.gartner.com/technology/itglossary/enterprise-architecture.jsp 
Government of South Australia. (2004). Emergency Management Act 2004 Retrieved Mar 30, 2011, from http://www.legislation.sa.gov.au/LZ/C/A/EMERGENCY MANAGEMENT ACT 2004.aspx

Guédria, W., Chen, D., \& Naudet, Y. (2009). A Maturity Model for Enterprise Interoperability. In R. Meersman, P. Herrero \& T. Dillon (Eds.), Lecture Notes in Computer Science (pp. 216225).

Heart, F., McKenzie, A., McQuillian, J., \& Walden, D. (1978). ARPANET Completion Report (4799). Burlington, MA.

IDEAS. (2003). IDEAS Project Deliverables (WP1-WP7), Public reports Retrieved Jul, 2011, from www.ideas-roadmap.net

Igarashi, Y., Kong, L., Yamamoto, L., \& McCreery, C.S. (2011). Anatomy of Historical Tsunamis: Lessons Learned for Tsunami Warning. Pure Applied Geophysics(168), 2043-2063. Iivari, Juhani. (1991). A Paradigmatic Analysis of Contemporary Schools of IS Development. Eur. J. Information Systems, 1(4), 249-272.

ISO. (2005). ISO14258 Industrial Automation Systems - Concepts and Rules for Enterprise Models.

ISO/IEC. (2005). Annex A: GERAM ISO/IS 15704:2000/Amd1:2005: Industrial automation systems - Requirements for enterprise-reference architectures and methodologies. Kapucu, Naim, Arslan, Tolga, \& Demiroz, Fatih. (2010). Collaborative emergency management and national emergency management network. Disaster Prevention and Management, 19(4), 452-468.

Keen, P.G.W., \& Scott Morton, M. (1978). Decision Support Systems: An Organisational Perspective. Reading, Massachussetts: Addison-Wesley.

Kilbourne, Edwin D. (2006). Influenza Pandemics of the 20th Century. Emerging Infectious

Diseases, 12(1).

Kristensen, Margit, Kyng, Morten, \& Palen, Leysia. (2006). Participatory Design in

Emergency Medical Service: Designing for Future Practice. Paper presented at the Conference on Human Factors in Computing Systems - CHI 2006, Montréal, Québec / Canada. Krogstad, U., Hofoss, D. , \& Hjortdal, P. (2004). Doctor and nurse perception of interprofessional co-operation in hospitals. International Journal for Quality Health Care, 16(6), 491-497.

McGregor, D. (1960). The Human Side of Enterprise. New York: McGraw-Hill. Mo, John. (2007). The use of GERAM for Design of a Virtual Enterprise for a Ship Maintenance Consortium. In Pallab Saha (Ed.), Handbook of Enterprise Systems Architecture in Practice (pp. 351-366). Hershey, USA: IDEA Group.

Moghadas, S.M., Pizzi, N.J., Wu, J., \& Yan, P. (2008). Managing public health crises: the role of models in pandemic preparedness. Influenza Other Respi Viruses, 3(2), 75-79.

Moore, Linda K. (2010). The Emergency Alert System (EAS) and All-Hazard Warnings

Retrieved May, 2013, from http://www.fas.org/sgp/crs/homesec/RL32527.pdf

Msanjila, S., \& Afsarmanesh, H. (2010). FETR: a framework to establish trust relationships among organizations in VBEs. Journal of Intelligent Manufacturing, 21, 251-265.

NATO. (2006). Interoperability for joint operations Retrieved July, 2011, from http://www.nato.int/docu/interoperability/interoperability.pdf

Neumann, D., de Santa-Eulalia, Luis Antonio, \& Zahn, Eric. (2011). Towards a Theory of Collaborative Systems. Paper presented at the Adaptation and Value Creating Collaborative Networks (Proceedings of the $12^{\text {th }}$ IFIP Working Conference on Virtual Enterprises - PROVE 11), São Paulo / Brazil.

Noran, O. (2008). A Meta-methodology for Collaborative Networked Organisations: Creating Directly Applicable Methods for Enterprise Engineering Projects. Saarbrücken: VDM Verlag Dr. Müller.

Noran, O. (2009). A Decision Support Framework for Collaborative Networks. International Journal of Production Research, 47(17), 4813-4832. 
Noran, O. (2011). Towards A Collaborative Network Paradigm for Emergency Services. Adaptation and Value Creating Collaborative Networks - IFIP Advances in Information and Communication Technology, 362, 477-485.

Noran, O. (2012a). Achieving A Sustainable Interoperability of Standards. Annual Reviews in Control, 36, 327-337.

Noran, O. (2012b). Collaborative networks in the tertiary education industry sector: a case study International Journal of Computer Integrated Manufacturing: Collaborative Networks as Modern Industrial Organisations: Real Case Studies, 26(1-2), 29-40.

Noran, O., \& Bernus, P. (2011). Effective Disaster Management: An Interoperability Perspective. Lecture Notes in Computer Science, 7046, 112-121.

NZ National Ethics Advisory Committee. (2006). Ethical Values for Planning for and Responding to a Pandemic in New Zealand Retrieved May, 2013, from http://neac.health.govt.nz/sites/neac.health.govt.nz/files/documents/publications/pandemicplanning-and-response.pdf

OASIS. (2005). Common Alerting Protocol v1.1, 2012, from http://www.oasisopen.org/committees/download.php/15135/emergency-CAPv1.1-Corrected_DOM.pdf Pava, C. (1983). Managing New Office Technology, An Organisational Strategy. New York: Free Press.

Pinto, H., Prez, A., \& Martins, J. (1999). Some Issues on Ontology Integration (Proceedings of IJCAI-99 workshop on Ontologies and Problem-Solving Methods (KRR5)). Stockholm, Sweden.

Prizzia, Ross, \& Helfand, Gary. (2001). Emergency preparedness and disaster management in Hawaii. Disaster Prevention and Management, 10(3), 163-172.

Queensland Floods Commission of Enquiry. (2011). Submissions to the Enquiry Retrieved July, 2011, from http://www.floodcommission.qld.gov.au/submissions/

Queensland Government. (2011). Queensland Combined Emergency Services Academy (QCESA) Retrieved Mar 30, 2011, from

http://www.safecom.sa.gov.au/site/emergency_management.jsp

Ramanujam, R., \& Rousseau, D.M. (2006). The Challenges Are Organizational, Not Just Clinical. Journal of Organizational Behavior, 27(7), 811-827.

Saha, Pallab. (2007). A Synergistic Assessment of the Federal Enterprise Architecture Framework against GERAM (ISO15704:2000 Annex A). In Pallab Saha (Ed.), Enterprise Systems Architecture in Practice (pp. 1-17). Hershey, USA: IDEA Group.

Shimada, Y., Kitajima, T., Fuchino, T., \& Takeda, K. (2012). Disaster Management Based on Business Process Model Through the Plant Lifecycle. In John Tiefenbacher (Ed.), Approaches to Managing Disaster - Assessing Hazards, Emergencies and Disaster Impacts. Rijeka: InTech. Stohr, E, \& Konsynsky, B. R. (1992). Information Systems and Decision Processes. California. Thompson, Alison K, Faith, Karen, Gibson, J, \& Upshur, Ross EG. (2006). Pandemic influenza preparedness: an ethical framework to guide decision-making. BMC Medical Ethics, 7(12). Tierney, K., \& Quarantelli, E. L. (1989). Needed Innovation in the Delivery of Emergency Medical Services in Disasters: Present and Future. Disaster Management, 2(2), 70-76. Trakas, Athina. (2012). Interoperability - A key requirement for emergency and disaster management, 2012, from http://www.un-spider.org/book/5143/4c-challenge-communicationcoordination-cooperation-capacity-development

U.S. Dept of Health and Human Services. (2005). HHS Pandemic Influenza Plan Retrieved May, 2013, from http://www.flu.gov/planningpreparedness/federal/hhspandemicinfluenzaplan.pdf

United Nations International Strategy for Disaster Reduction Secretariat (UNISDR). (2011). Hyogo Framework for Action 2005-2015: Building the resilience of nations and communities to disasters Retrieved Mar 30, 2011, from http://www.preventionweb.net/files/1037_hyogoframeworkforactionenglish.pdf 
Utah Department of Health. (2007). Governor's Task Force for Pandemic Influenza Preparedness - Final report to Governor Retrieved April, 2013, from http://pandemicflu.utah.gov/docs/PandInfluTaskforceFinalReport.pdf Vernadat, F. (1996). Enterprise Modelling and Integration: Principles and Applications. London: Cpmn \& Hall.

Victorian Bushfires Royal Commission. (2009). Submissions to the Enquiry Retrieved July, 2011, from http://www.royalcommission.vic.gov.au/Submissions/View-Submissions von Lubitz, Dag K.J.E. , Beakley, James E., \& Patricelli, F. (2008). Disaster Management: The Structure, Function, and Significance of Network-Centric Operations. Journal of Homeland Security and Emergency Management, 5(1), Art 42.

Waugh, William L. (1993). Coordination or Control: Organizational Design and the Emergency Management Function. Int Journal of Disaster Prevention and Management, 2(4), 17-31. Whitman, L., \& Panetto, H. (2006). The Missing Link: Culture and Language Barriers to Interoperability. Annual Reviews in Control, 30(2), 233-241.

Wickramasinghe, N, \& von Lubitz, Dag K.J.E. . (2007). Knowledge Based Enterprises:

Theories and Fundamentals (Vol. 5). Hershey PA: IGP Publishing Group,.

Wiese, C. R. (2006). Organizing Homeland Security after Katrina: is adaptive management what's missing? Public Administration Review, 66(3), 302-318.

Wilson, K., Coulon, L., Hillege, S., \& Swann, W. (2005). Nurse Practitioners' Experience of Working Collaboratively with General Practitioners and Allied Health Professionals in NSW, Australia. Australian Journal of Advanced Nursing, 23(2), 22-27.

World Health Organisation. (2011). Pandemic Influenza preparedness Framework Retrieved May, 2013, from http://whqlibdoc.who.int/publications/2011/9789241503082_eng.pdf World Health Organization. (1998). The world health report 1998---life in the 21st century: a vision for all Retrieved April, 2013, from http://www.who.int/whr/1998/en/whr98_en.pdf 